\title{
Technical Change And Growth In The Textile Industry: The Nonwoven Sector
}

Susan Christoffersen, (Email: Christoffersens@PhilaU.edu), Philadelphia University Anusua Datta, (Email: DattaA@PhilaU.edu), Philadelphia University

\begin{abstract}
We examine the performance of a growing sector of the textile industry: nonwoven fabric mills. This sector is emerging from what was once a marginal manufacturing sector to become increasingly a focus for the future of textiles in the US. From disposable diapers to bleach wipes, medical apparel to house wrapping, new products are entering the market; these products are made possible by technological advancements in adhesion techniques, fiber modifications and delivery advancements. In order to better understand these significant industry dynamics, we estimate a translog cost function to calculate the elasticity of substitution between capital, labor, energy and materials and to see how these change over time. Additionally, we track trends in the elasticity of scale and the impact of technological change. Textile manufacturing in the United States is shifting away from commodity products and the innovative nonwovens sector provides a much needed exemplar for future textile manufacturing.
\end{abstract}

\section{INTRODUCTION}

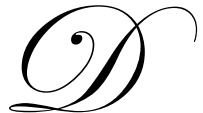

ire news regarding the U.S. textile industry is manifest. At the aggregate industry level, many of these claims are correct. However, a very different picture emerges from data from the individual sectors of the textile industry where there is tremendous creative energy. Levinsohn and Petropolous (2001) present the industry as an example of "creative destruction", a term made famous by Joseph Schumpeter. His idea is that the creation of new products and production methods lead to the destruction of market share for firms committed to existing paradigms. The evolution of the nonwoven sector in the last thirty years has certainly been creative and is changing textile manufacturing in the United States.

\section{THE NONWOVEN MANUFACTURING SECTOR}

\section{The Importance Of The Nonwovens Sector}

The textile industry is an important manufacturing sector; it contributed close to $\$ 69$ billion to GDP in 2005 (BEA, 2007); in certain regions of the United States, it is the predominant employer although those numbers are declining. Within the textile industry, the nonwovens sector is distinguished for its growth; this is in contrast to many other textile sectors. In 2002, the sector employed more than 21,000 employees (Census, 2007) ${ }^{1}$ at average wage rates above the typical textile worker. The following graph, Figure 1, tracks the changes in employment from 1958 through 1996.

\footnotetext{
${ }^{1}$ The US Census Bureau conducts surveys every 5 years, the next survey will be distributed Dec. 2007, making data from 2002 the most current. The graphs show data until 1996 as the Standard Industrial Code (SIC) was replaced at that time by the North American Industrial Classification System (NAICS) which does not yet contain enough years to perform significant statistics. SIC 2297is not equivalent to NAICS 313230 as the later also contains data for miscellaneous textiles, SIC 2299.
} 


\section{Employment in the Nonwoven Sector}

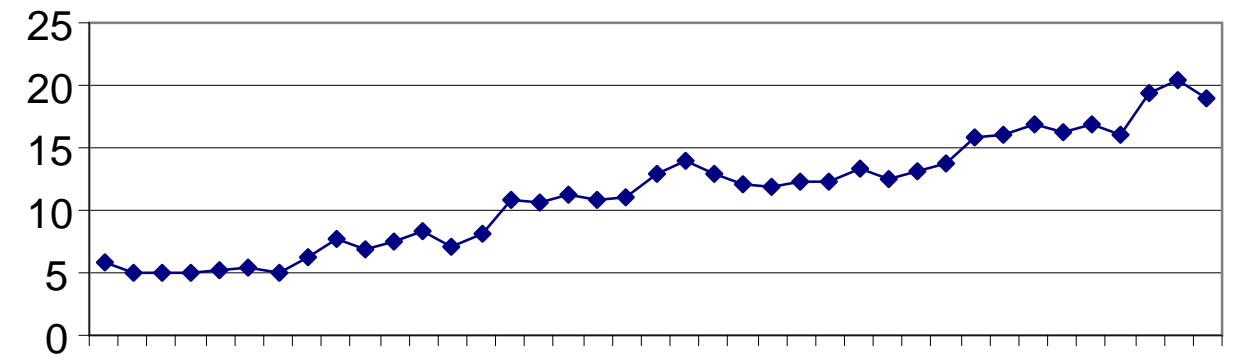

5860626466687072747678808284868890929496 1958-1996

The number of firms entering the industry continues to grow as does sales volume, measured by value of shipments in Figure 2, as new uses of nonwovens continue to be developed.

Figure 2: Output of Nonwoven Sector (millions)

\section{Value of Shipments by the Nonwoven Sector}

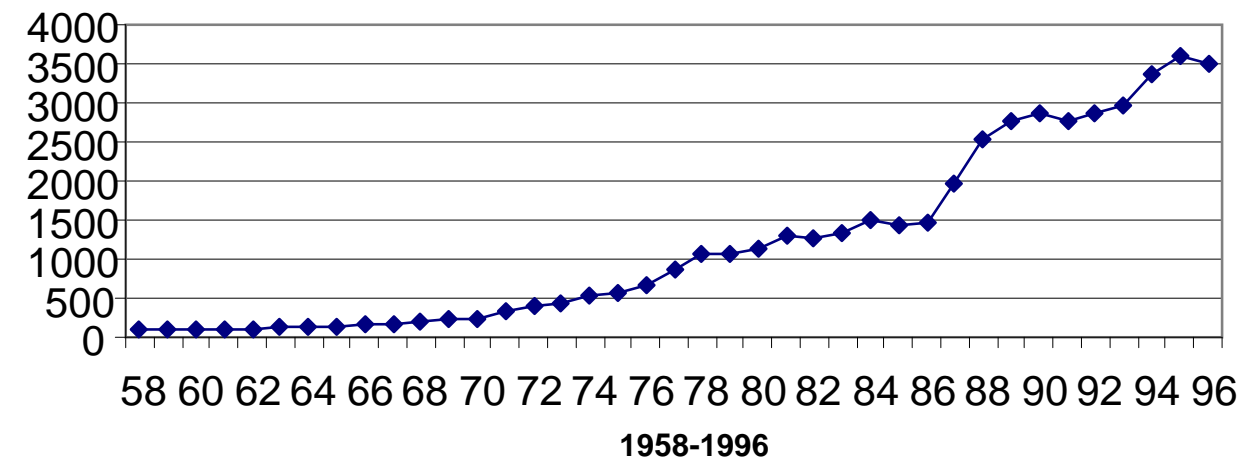

Source: NBER Manufacturing Productivity Database

The following table shows these trends relative to the textile industry as a whole. 
Figure 3: Growth of the Nonwovens Sector

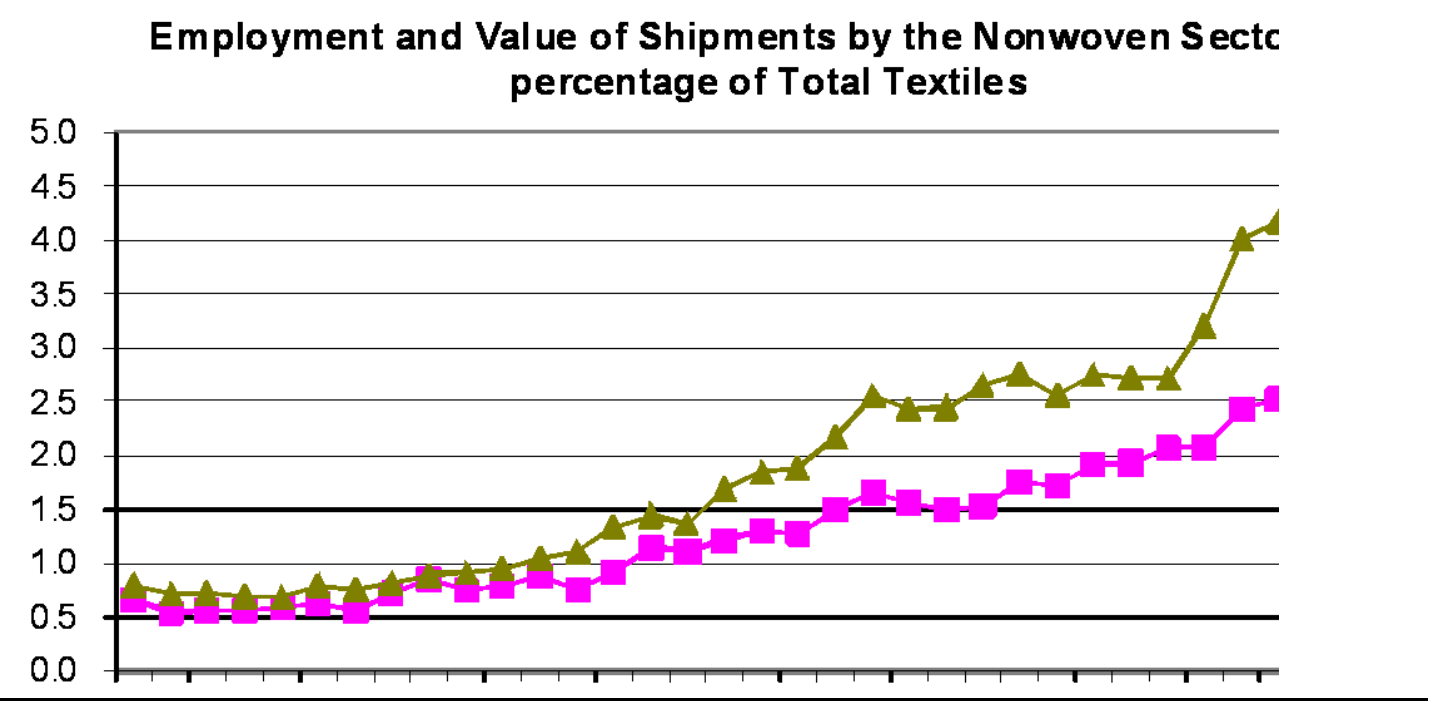

Source: NBER Manufacturing Productivity Database

\section{Evolution Of Nonwoven Products And Production Costs}

In the 1950's, the Kendall Co. produced a nonwoven cotton cloth to clean photographic plates that was superior to the rolled cotton used previously. In the early 1970's, growth accelerated due to process innovations that lead to the introduction of disposable diapers. (source?). Later, the nonwovens sector included molded car interiors, house wrap, industrial and medical apparel. Products evolve as the cost, performance and product characteristics benefit from technological advances in formation processes.

At the same time that production processes and products were swiftly evolving, energy and labor prices were also increasing, outpacing increases in the final prices for output. The chart below highlights these price pressures.

Figure 3: Price Indices for Nonwovens

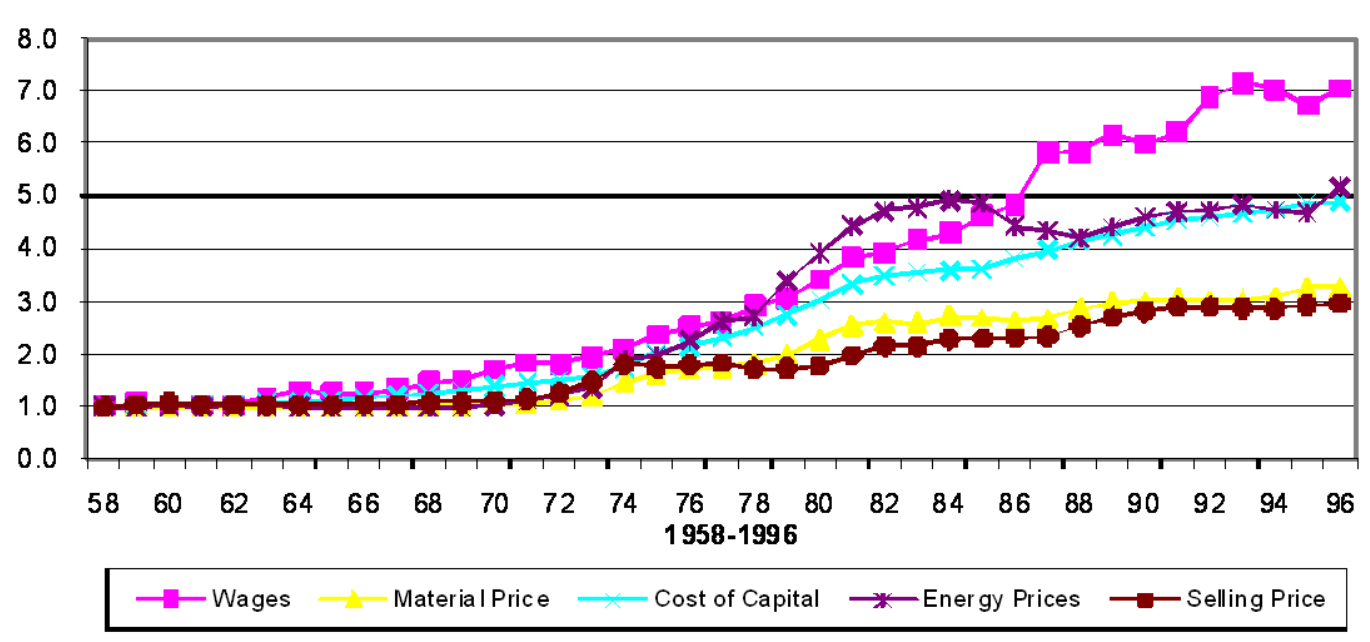

Source: Bureau of Labor Statistics, http://bls.gov 
The price index for labor shows the greatest increase over the period. The second greatest increase is in the price of energy, which is also the most variable, however not a significant share of the overall cost structure facing the firm, as illustrated in the following chart. Similarly, the increase in the price of investment in capital is large but again not a large expenditure relative to total costs. The most modest price increase is for the final product; good news for the consumer but not the manufacturer. Nonwoven prices for the final goods increased by $196 \%$ while overall, the cost of commodities increased 305.8\% between 1965 and 2002 (Carpet \& Rug Institute, 2003).

While these profiles are not uncommon within the textile industry, there are two substantial differences in the nonwovens sector. First, the cost of material very closely tracks the price index for shipments (the price of the final product). The general pattern in textiles is for material costs to increase by much more than output prices. Secondly, the capital intensive manufacturing protects the nonwovens sector from much of the competition from abroad. Governments of developing countries tend to avoid subsidizing industries requiring large capital investments and small workforces; they generally have the objective of increasing employment opportunities for their labor force.

The following chart shows the importance of materials in the cost structure.

Figure 4: Sum of Costs and Value Added

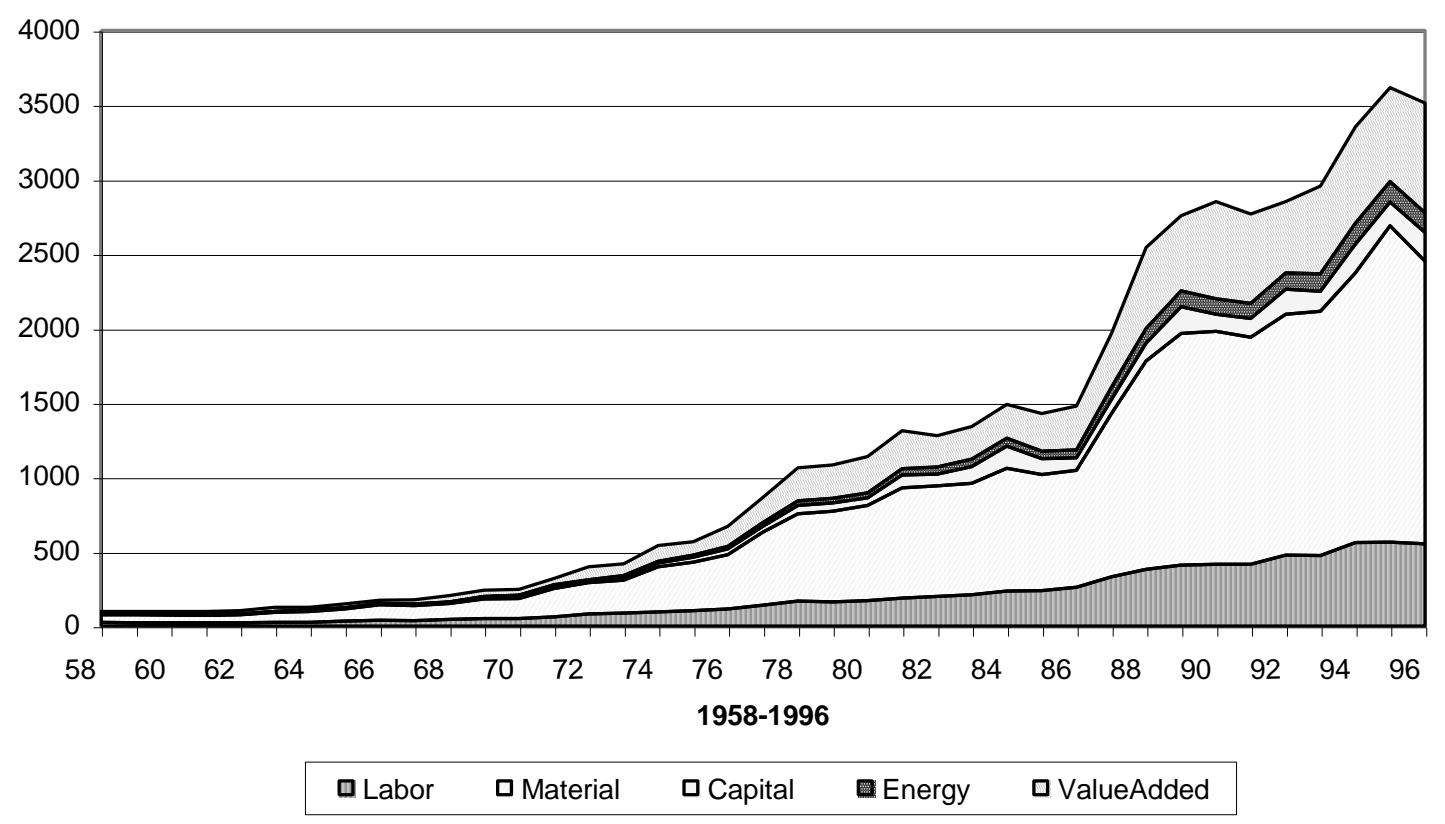

Source: NBER Manufacturing Productivity Database

Material costs went from 65 to 70 percent of the costs of production, while labor shifted from 30 to 20 percent of the costs, and the rest is accounted for by energy and capital, which together went from $5 \%$ to $10 \%$ of the total cost of production.

Thus we observe a) large changes in the relative prices of inputs and b) the importance of materials in the cost structure of the firm. Rising labor costs favor the labor-saving technology of the nonwovens processes. Technological innovations in the production process continue to encourage growth in the industry with new product development and product quality improvements. We apply econometric techniques to analyze this sector's success, 
particularly with regard to changing patterns of input use, that is, the degree of substitutability between inputs as costs change, as well as determine the economies of scale.

Next, we first present the theoretical model and the description of the dataset. Then the econometric estimation and analysis of the nonwoven sector provides insight for textile manufacturing in the future.

\section{ECONOMETRIC ANALYSIS}

\section{Theoretical Model}

We employ the transcendental logarithmic (translog) cost function to study the production structure of the nonwoven sector. The translog cost function developed by Christensen, Jorgensen and Lau [1971, 1973] handles multiple inputs and allows for variable elasticities of substitution between these inputs. This is preferable to the Cobb-Douglas and constant elasticity of substitution (CES) production functions that only allow us to analyze two inputs, usually capital and labor, and restrict the elasticity parameters to sum to unity (Cobb-Douglas) or be constant (CES). ${ }^{2}$

Assuming firms minimize total costs of production, the general form of the aggregate cost function can be represented as

$\min C=G\left(P_{K}, P_{L}, P_{E}, P_{M}, Q, T\right)$

where production cost $(C)$, is expressed as a function of the prices of inputs (capital, labor, energy, materials), the level of output (Q) and technical change (T). The general form of the cost function is expressed in its translog form [Christensen et al. (1973)] as

$$
\begin{aligned}
\ln C=\alpha_{0} & +\alpha_{q} \ln Q++\Sigma_{i} \alpha_{i} \ln P_{i}+1 / 2 \gamma_{q q}(\ln Q)^{2} \\
& +1 / 2 \Sigma_{i} \Sigma_{j} \gamma_{i j} \ln P_{i} \ln P_{j}+\Sigma_{i} \gamma_{i q} \ln P_{i} \ln Q \\
& +\Sigma \theta_{i t} \ln P_{i} T+\theta_{q t} \ln Q T+\beta_{t} T+1 / 2 \beta_{t t} T^{2}
\end{aligned}
$$

where $i, j=K, L, E, M$, and $\alpha, \beta, \gamma, \theta$ are the parameters to be estimated. To streamline the exposition, econometric specifics are articulated separately in the following sections of the econometric results, and in full in the appendix.

The model is estimated using the iterative Zellner procedure for seemingly unrelated regressions using the RATS software. The estimated cost function is a multi-input, non-homothetic function, which allows for nonconstant returns to scale, non-neutral technical progress and variable elasticity of substitution.

\section{Data Sources}

This study is based on data for the period 1953-1996. Data on cost and prices of labor, capital service, energy, non-energy materials and real output for nonwoven textiles (SIC 2297) are taken from the Bureau of Labor Statistics' Multifactor Productivity database. Total cost is computed as the total of labor, capital, energy and material cost. Using this data to estimate the parameters of the cost function allow us to investigate the sources of growth for the nonwovens sector. Specifically, we investigate whether this sector was able to take advantage of economies of scale and how technical change over time has altered the optimal combination and level of inputs.

\footnotetext{
${ }^{2}$ For a detailed discussion see Fuss, McFadden and Mundlak (1978), pp. 224-225, and Lau (1986), pp. 1515-1564.
} 


\section{Econometric Estimation And Analysis}

Economies of Scale

Scale economies (SE) are measured as the reciprocal of elasticity of $\operatorname{cost}\left(\varepsilon_{C Q}\right)$ or the percentage change in cost with respect to output, holding input prices and technology constant

$\mathrm{SE}=\left[\frac{\partial \ln C}{\partial \ln Q}\right]^{-1}=\left[\alpha_{q}+\sum \gamma_{i q} \ln P_{i}+\gamma_{q q} \ln Q+\theta_{i} T\right]^{-1}$

Constant returns to scale are indicated by $\mathrm{SE}=1$; costs increase in direct proportion to output. Decreasing returns to scale are indicated by a parameter value $\mathrm{SE}<1$, that is, costs increase more than proportionate to the increase in output. Our estimates yield the following results.

\section{Economies of Scale}

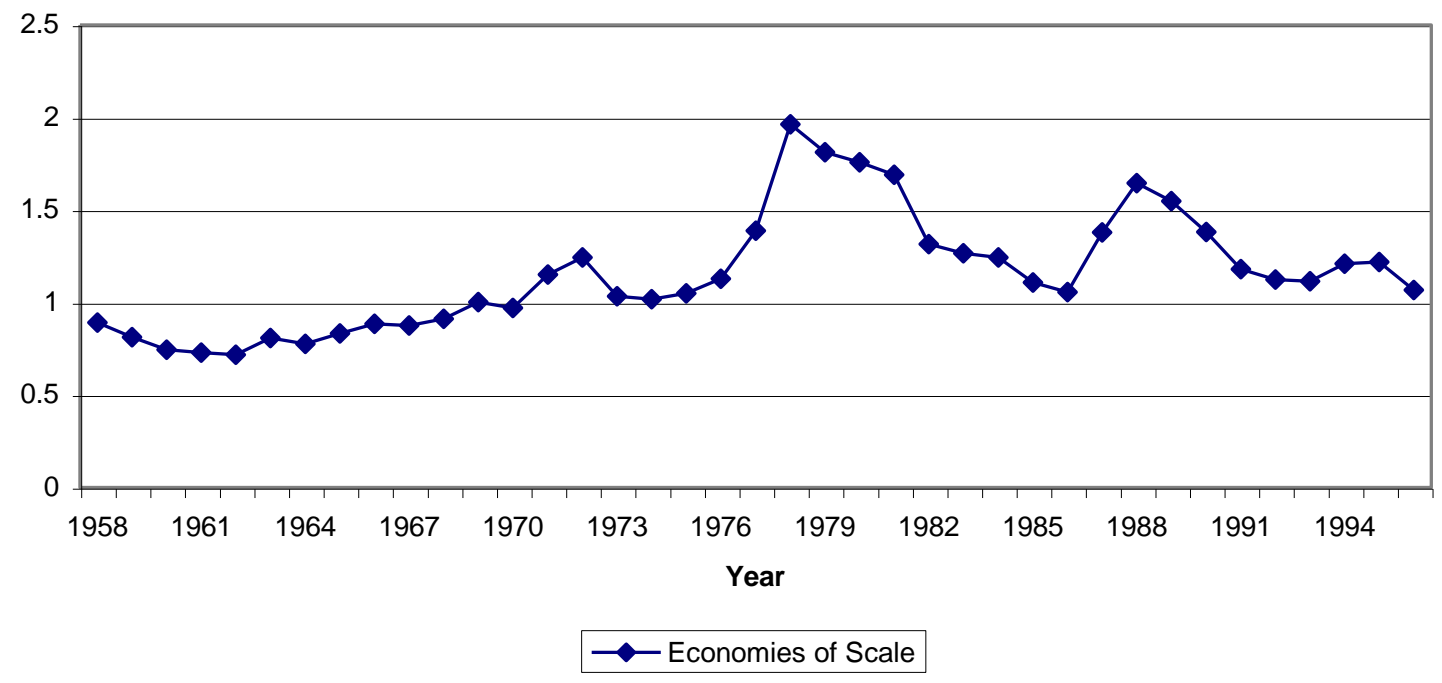

We observe decreasing returns to scale in the nonwoven sector up until the 1970's. Before the 1970's, one would expect firms to be operating at full capacity; expansion causing pressure on the costs. After 1975, however, we see a transformation; SE >1, implying increasing returns to scale. There is sufficient capacity that if the firm expands the scale of operation, they would experience falling per unit costs consistent with a capital intensive industry, requiring large fixed costs. The industry became more efficient between 1978 and 1996, as demand for the nonwoven products grew and mass production allows the firms to take advantage of the scale economies.

\section{Technical Change}

The rate of technical change (TC) equals the negative of the rate of growth of total cost with respect to time, holding output and prices of all inputs constant. In terms of the translog cost function, the rate of technical change is measured as,

$\mathrm{TC}=-(\partial \ln C / \partial T)=-\left[\beta_{t}+\sum \theta_{i t} \ln P_{i}+\theta_{q t} \ln Q+\beta_{t t} T\right]$ 
In equation (4) the parameters $\beta_{t}$ and $\beta_{t t}$ measure neutral shifts in the cost function. Thus if $\beta_{t}<0$ and $\beta_{t t}>0$, it implies costs decrease over time at an increasing rate, while $\beta_{t}<0$ and $\beta_{t t}<0$ implies costs decrease but at the decreasing rate. $\theta^{\prime} s$ measure the biases in technical progress. Technical change is $i$ th factor saving if $\theta_{i t}<0$ and factor using if $\theta_{i t}>0$.

Both $\beta_{t}$ and $\beta_{t t}$ are negative and significant in our model estimates (Table 1, appendix), which indicates that production costs are going down over time in the nonwoven sector, but at a decreasing rate. The rate of technical progress for the sample period 1958-1996 averages around $0.4 \%$. This includes periods of negative technical progress (increasing costs) in the late 1970s and mid-1980s, possibly representing periods of energy price shocks and capital investment (see chart below).

\section{Technical Change}

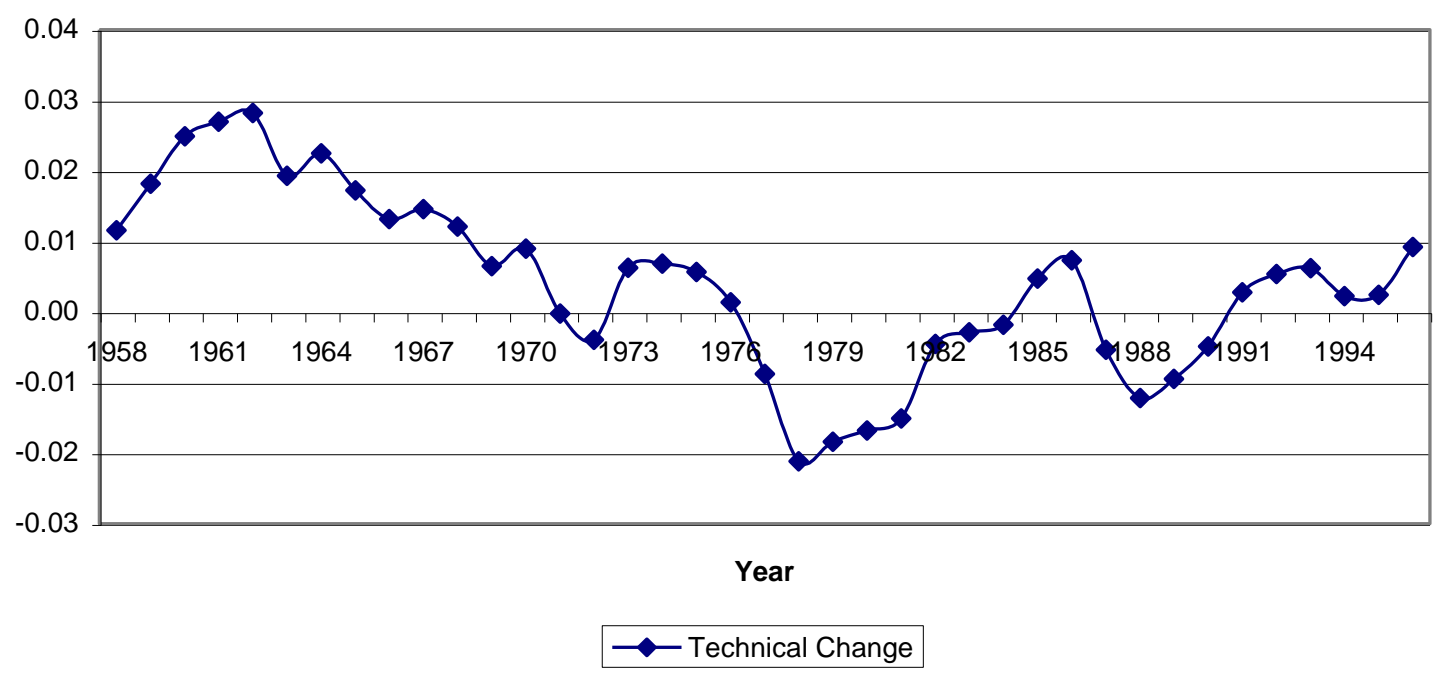

For this sector we find $\theta_{K T}<0$ and $\theta_{E T}>0$ which indicate capital-saving and energy using technical progress. An increase in the price of capital encourages the substitution of other inputs which makes the adoption of capital-saving technology more cost effective; this may be attributed to the growing importance of material and labor in the cost structure. Again we see a shift in technology taking place around 1970; the energy using component may be attributed to the increased fuel prices at the time.

\section{Elasticities of Substitution}

The cost function also yields direct estimates of the various Allen-Uzawa elasticities of substitution. These parameters are the key to describing the pattern and degree of substitutability and complementarity between the factors of production. The Allen-Uzawa partial elasticities of substitution between two factors $i$ and $j, \square_{i j}$, can be computed directly from the translog cost function [Nadiri and Schankerman, 1981].

$$
\sigma_{i j}=\frac{\gamma_{i j+} S_{i} S j}{S_{i} S_{j}} ; \quad \text { for } i \neq j
$$


Having four inputs (labor, materials, capital and energy) creates six pairs for which we estimate elasticities of substitution. To present the results in as clear a manner possible, we segment the elasticities by whether or not energy is in the pair. A positive elasticity indicates that the inputs are substitutes, a negative estimate indicates complements.

\section{Substitution Elasticities: Energy}

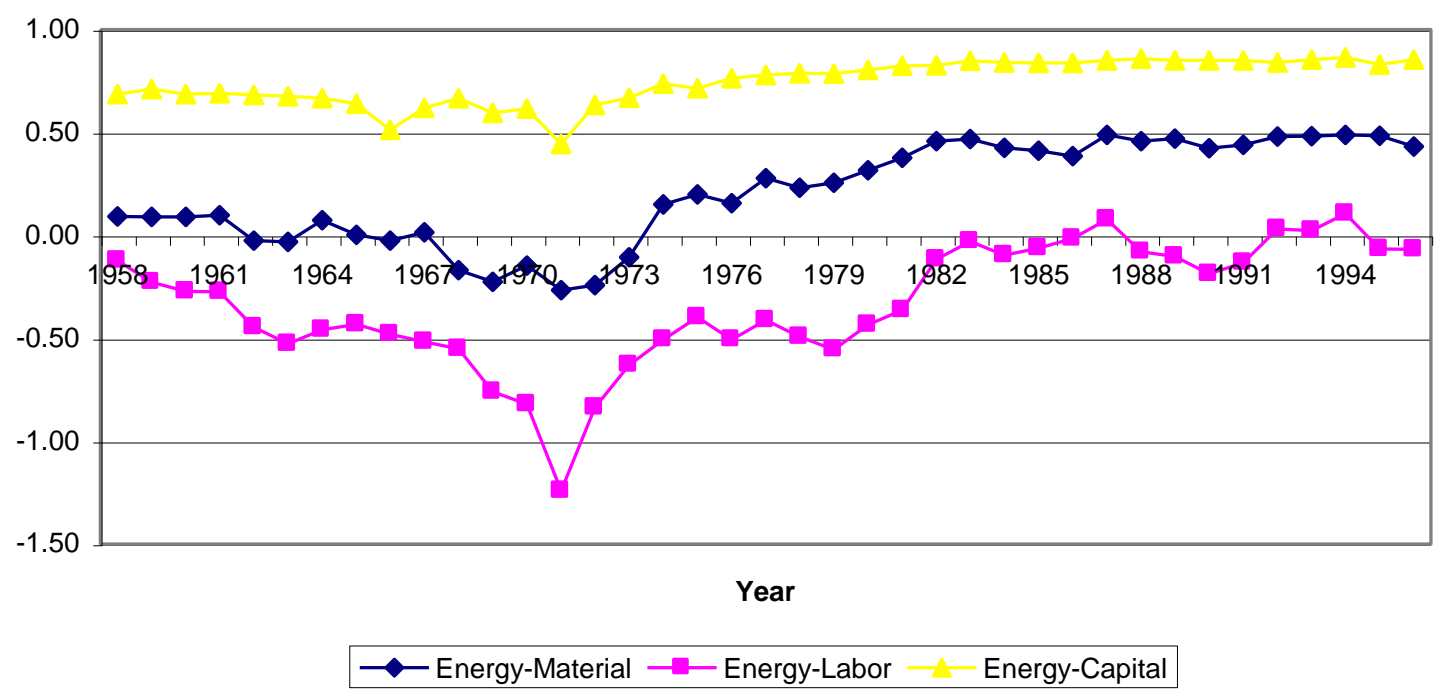

Once again a change in technology is in evidence in the early 1970's, energy and materials switch from complements to substitutes. Previous to 1974 , if one were to increase production, using more labor or material, one would necessarily use more energy. After 1974, one could substitute more capital or material for energy, perhaps indicating new energy saving capital investment.

\section{Substitution Elasticities: Non-Energy}

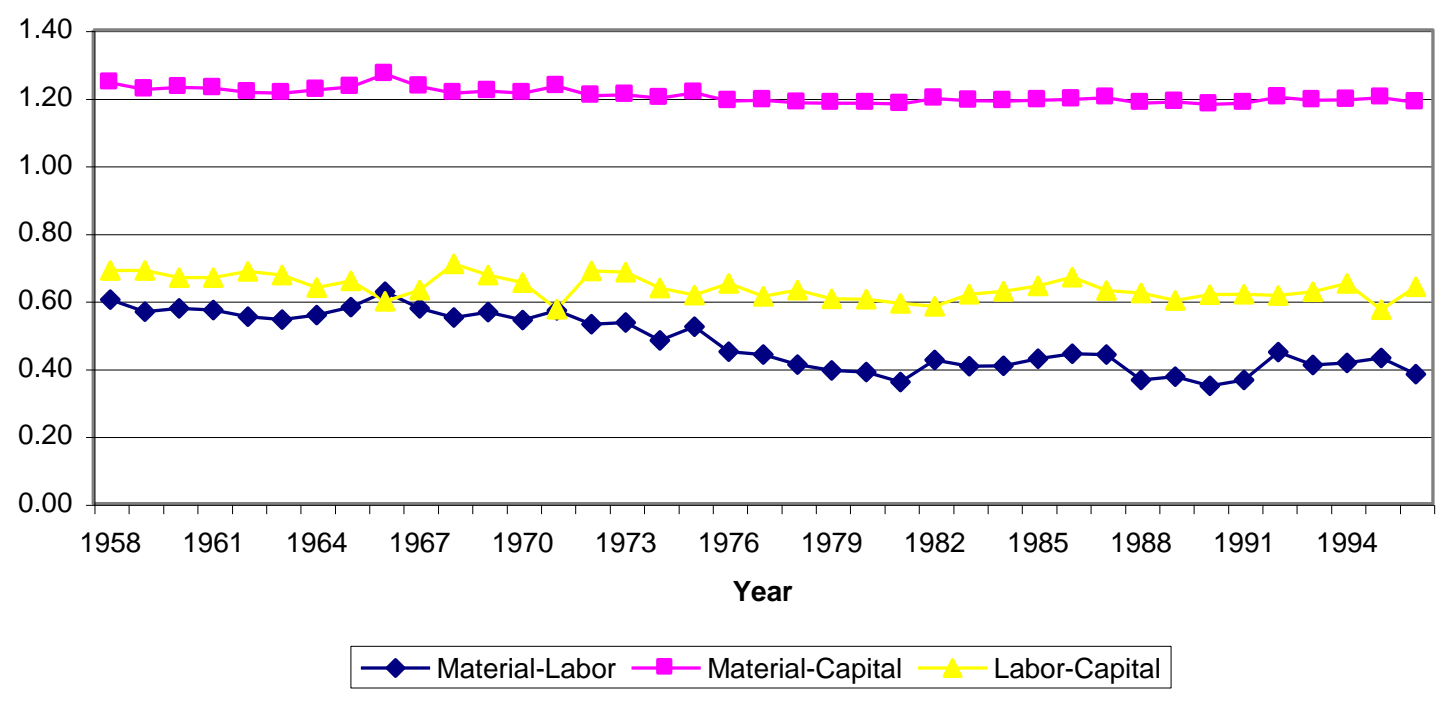


While material and capital remain highly substitutable, substitution elasticity between material and labor declines in production. This period covers a technological transition to greater degrees of capital intensity in production. As fewer workers are involved with the production process, they are more critical and less substitutable for other inputs.

The high degree of substitutability between materials and capital might at first blush seem counterintuitive; how can one use more machines and less fiber to achieve a certain level of production? Could one produce the same amount of sweaters, for example, with more looms and less wool? The degree to which capital and material are not complements perhaps reflects the ability of the industry to outsource; that is "to make or buy". If they are making the intermediate inputs, they invest in capital; if the prices shift, an agile manufacturer buys the intermediate inputs (material), thereby substituting material for capital.

\section{CONCLUSIONS}

Clearly there has been a fundamental transformation in the nonwovens sector. We attribute this to both product and process innovations. Existing products are being improved (diapers) and new products are continually arising (Clean-up wipes). This is clearly reflected in the data. After 1975, there is a shift to increasing returns to scale in production; there is sufficient capacity that as the scale of operation expands, unit costs fall, consistent with mass production and the large fixed costs of high tech production. Process innovations are evidenced by a shift in technology taking place around 1970 with the growing importance of material and labor in the cost structure. At the same time, energy and materials switch from complements to substitutes. After 1974, one could substitute more capital or material for energy, perhaps indicating new energy saving capital investment.

Material and labor become less substitutable in production; there is a greater degree of capital intensity in production so as fewer workers are involved, they are more critical and less substitutable for other inputs. One would expect capital and material to be used together (complements) but they are substitutes. This reflects the ability of the industry to outsource; that is the "make or buy" decision. Nonwovens, a growing sector of the textile industry, is a paradigm for growth; it exemplifies the value of innovation in an industry often mistakenly dismissed as "old manufacturing".

\section{ACKNOWLEDGEMENTS}

This research was supported by grants from the National Textile Center. We gratefully acknowledge their support as well as the support of Philadelphia University. We thank Mikhail Kouliavtsev (Stephen F. Austin State University) and faculty members at Philadelphia University's School of Business Administration; they were most helpful. All errors remain our own.

\section{REFERENCES}

1. ATMI (2001, August). Crisis in U.S. Textiles. Report: Office of the Chief Economist and the International Trade Division of the American Textile Manufacturers Institute.

2. Bartlesman, E.J. and W. Gray. 1996. The NBER Manufacturing Productivity Database. NBER Technical Working Paper 205.

3. Carpet \& Rug Institute. 2004. Sustainability Report 2003 http://www.carpet-rug.org ch.VII Economics.

4. Cline, William R. 1990. The Future of World Trade in Textiles and Apparel, Institute of International Economics, Washington, D.C.

5. Chmura, C. 1985. The Textile and Apparel Industries: Technological Transition. Cross Section, 2 (2): 1, 5, 12 (Federal Reserve Bank of Richmond).

6. Christensen, L.R., D.W. Jorgensen and L.J. Lau. 1971. Conjugate Duality and the Transcendental Logarithmic Production Function. Econometrica, 39: 255-256.

7. Christensen, L.R., D.W. Jorgensen and L.J. Lau. 1973. Transcendental Logarithmic Production Frontiers. Review of Economics and Statistics, 55(1): 28-45. 
8. Christoffersen, S. and A. Datta. 2003. The Changing Structure of U.S. Textiles: Productivity Implications. Journal of Business and Economic Studies.

9. Datta, A. 2003. Divestiture and Its Implications for Innovation and Productivity Growth in U.S. Telecommunications. Southern Economic Journal, 69(3): 644-658.

10. Diewert, W. E. 1971. An Application of Shephard's Duality Theorem: A Generalized Leontief Production Function. Journal of Political Economy, 79(3): 461-507.

11. Fairchild's Textile and Apparel Financial Directory (1989/1990). New York: Book Division, Fairchild Publications.

12. Fuss, M.A., D.L. McFadden and Y. Mundlak. 1978. A Survey of Functional Forms in the Economic Analysis of Production, in Fuss and McFadden eds. Production Economics: A Dual Approach to Theory and Applications, Vol. 1, North Holland: Amsterdam, pp 219-68.

13. Kmenta, J. and R. Gilbert. 1968. Small Sample Properties of Alternative Estimators of Seemingly Unrelated Regressions. Journal of American Statistical Association, 63:1180-1200.

14. Lau, L.J. 1986. Functional Forms in Econometric Model Building, in Griliches and Intriligator eds. Handbook of Econometrics, Vol 3, North Holland: Amsterdam.

15. Levinsohn J. and W. Petropolous, 2001. Creative destruction or just plain destruction? The U.S. Textile and Apparel Industries Since 1972, NBER, Working Paper 5348, Cambridge, MA.

16. Nadiri, M.I. and M.A. Schankerman. 1981. The Structure of Production, Technological Change and the Rate of Growth of Total Factor Productivity in the U.S. Bell System, in Cowing and Stevenson, eds. Productivity Measurement in Regulated Industries, Academic Press: New York, pp 219-246.

17. Morrison Paul, C. J. 2003. Cost Economies: A Driving Force for Consolidation and Concentration? Southern Economic Journal, 70(1): 110-127.

18. Ramcharran, H. 2001 a. Estimating Productivity and Returns to Scale in the U.S. Textile Industry, Empirical Economics, 26(3): 453-60.

19. The Economist. 2004. Special Report: The textile industry: The looming revolution. November 13.

20. Improved Annual Industry Accounts for 1998-2003: Integrated Annual Input-Output Accounts and GrossDomestic-Product-by-Industry Accounts. (by Moyer, B.C., M.A. Planting, P.V. Kern, and A.M. Kish): p. 36.

21. U.S. Bureau of Economic Analysis. June 2007 Integrated Annual Input-Output Accounts and GrossDomestic-Output-by-Industry Accounts. http://bea.gov/industry/xls/GDPbyInd_VA NAICS 19982006.xls

22. Vinod, H.D. 1972. Non-Homogeneous Production Functions and Applications to Telecommunications. Bell Journal of Economics and Management Science, 3: 531-43.

23. Xia, Y. and S. Buccola. 2003. Factor Use and Productivity Change in Alcoholic Beverage Industries, Southern Economic Journal, 70(1): 93-109.

24. Zellner, A. 1962. An Efficient Method of Estimating Seemingly Unrelated Regression and Tests for Aggregation Bias. Journal of American Statistical Association, 57: 348-368.

\section{APPENDIX}

The cost function is expressed in its translog form, a second-order approximation to an arbitrary twicedifferentiable surface [Christensen et al. (1973)]:

$$
\begin{aligned}
\ln C=\alpha_{0} & +\alpha_{q} \ln Q++\Sigma_{i} \alpha_{i} \ln P_{i}+1 / 2 \gamma_{q q}(\ln Q)^{2} \\
& +1 / 2 \Sigma_{i}{ }_{j} \gamma_{i j} \ln P_{i} \ln P_{j}+\Sigma_{i} \gamma_{i q} \ln P_{i} \ln Q \\
& +\Sigma \theta_{i t} \ln P_{i} T+\theta_{q t} \ln Q T+\beta_{t} T+1 / 2 \beta_{t t} T^{2}
\end{aligned}
$$

where $i, j=K, L, E, M$, and $\alpha, \beta, \gamma, \theta$ are the parameters to be estimated.

For a well-behaved cost function, linear homogeneity in input prices and symmetry of the input-price Hessian matrix are imposed. 
(i) Linear homogeneity: $\sum \alpha_{i}=1 ; \sum \gamma_{i j}=\sum \gamma_{i q}=0 ; \sum \beta_{i}=0 ; \sum \theta_{i}=0$

(ii) Symmetry: $\gamma_{i j}=\gamma_{j i} \quad i \neq j$

The total cost function is estimated with the cost share equations obtained using Shephard's lemma [Diewert, 1971] $]^{3}$, by differentiating Eq. (2) with respect to the input prices.

$$
S_{i}=\frac{\partial \ln C}{\partial \ln P_{i}}=\alpha_{i}+1 / 2 \sum \gamma_{i j} \ln P_{j}+\gamma_{i q} \ln Q+\theta_{i} T \quad i, j=K, L, E, M
$$

where $S_{i}=P_{i} X_{i} / C$ is the share of costs accounted for by factor $i$. The cost share equations must satisfy the addingup criteria i.e. $\sum S_{i}=1$.

Scale economies (SC) are measured directly as the reciprocal of elasticity of $\operatorname{cost}\left(>_{C Q}\right)$ with respect to output,

$$
\mathrm{SC}=\left[\frac{\partial \ln C}{\partial \ln Q}\right]^{-1}=\left[\alpha_{q}+\sum \gamma_{i q} \ln P_{i}+\gamma_{q q} \ln Q+\theta_{i} T\right]^{-1}
$$

which vary with relative factor prices and the levels of output and technology. If SE is greater (less) than unity, cost increases less (more) than proportionally, implying the existence of increasing (decreasing) returns to scale.

The rate of technical change $(T C)$ equals the negative of the rate of growth of total cost with respect to time, holding output and prices of all inputs constant.

$T C=-\frac{\partial \ln C}{\partial T}=-\left[\beta_{t}+\sum \theta_{i t} \ln P_{i}+\theta_{q t} \ln Q+\beta_{t t} T\right]$

In equation (7), $\theta^{\prime} s$ measure the biases in technical progress. Technical change is ith factor saving if $\theta_{i t}<0$ and factor using if $\theta_{i t}>0$. The parameters $\beta_{t}$ and $\beta_{t t}$, measure neutral technical change, characterized by pure shifts in the cost function.

The Allen-Uzawa partial elasticities of substitution between two factors $i$ and $j, \square_{i j}$, and the outputcompensated own- and cross-price elasticities of factor demand, $\square_{i i}$ and $\square_{i j}$, can be computed directly from the translog cost function [Nadiri and Schankerman, 1981]. These parameters describe the degree of substitutability and complementarity between the factors of production.

$$
\sigma_{i j}=\frac{\gamma_{i j+} S_{i} S j}{S_{i} S_{j}} ; \varepsilon_{i j}=\frac{\gamma_{i j+} S_{i} S j}{S_{i}} \text { and } \varepsilon_{i i}=\frac{\gamma_{i i+} S_{i}^{2}-S_{i}}{S_{i}} \quad \text { for } i \neq j
$$

The equality $\sigma_{i j}=\sigma_{j i}$ is ensured by the condition $\gamma_{i j}=\gamma_{j i .}$ Also note that $\varepsilon_{i j}=S_{j} \sigma_{i j}$.

$3 \frac{\partial C(q, p)}{\partial P_{i}}=x_{i}(q, p)$, where $q$ represents output level and $p$ is a vector of input prices. 
The adding-up condition for the cost shares in (5) renders the disturbance covariance matrix to be singular. Therefore the system of equations is estimated by deleting one of the share equations. The model is estimated using the Iterative Zellner procedure for seemingly unrelated regressions with restrtictions (3) and (4) imposed using the RATS software. Kmenta and Gilbert [1968] show that iteration of the Zellner procedure until convergence yields maximum likelihood estimated which is invariant to the choice of equation deleted. The estimated cost function is a multi-input, non-homothetic function, which allows for non-constant returns to scale, non-neutral technical progress and variable elasticity of substitution.

Table 1: Model Estimates

\begin{tabular}{|c|c|c|}
\hline \multicolumn{3}{|c|}{ Textile-2297 Variable } \\
\hline Parameter & Coefficient & t-statistics \\
\hline$\square \square$ & -14.779 & $-6.71^{* * *}$ \\
\hline$\square \mathrm{e}$ & 0.088 & $6.87^{* * * *}$ \\
\hline$\square \mathrm{m}$ & 0.501 & $5.15^{* * *}$ \\
\hline$\square 1$ & 0.588 & $10.82^{* * *}$ \\
\hline$\square \mathrm{k}$ & -0.177 & $-1.88^{* * *}$ \\
\hline$\square \mathrm{q}$ & 6.511 & $7.99^{* * * *}$ \\
\hline$\square \mathrm{t}$ & -0.338 & $-5.48^{* * *}$ \\
\hline$\square$ ee & 0.019 & $6.38^{* * *}$ \\
\hline$\square \mathrm{mm}$ & 0.031 & 1.18 \\
\hline$\square 11$ & 0.144 & $3.67^{* * * *}$ \\
\hline$\square \mathrm{kk}$ & -0.010 & -0.58 \\
\hline$\square \mathrm{qq}$ & -1.003 & $-6.61^{* * *}$ \\
\hline$\square \mathrm{em}$ & -0.011 & $-1.64 *$ \\
\hline$\square \mathrm{el}$ & -0.006 & -1.46 \\
\hline$\square \mathrm{ek}$ & -0.002 & -1.05 \\
\hline$\square \mathrm{ml}$ & -0.049 & $-2.52^{* * *}$ \\
\hline$\square \mathrm{mk}$ & 0.028 & $1.78^{*}$ \\
\hline$\square \mathrm{lk}$ & -0.017 & $-1.86^{* *}$ \\
\hline$\square$ eq & -0.013 & $-6.79^{* * *}$ \\
\hline$\square \mathrm{mq}$ & 0.003 & 0.15 \\
\hline$\square \mathrm{lq}$ & -0.060 & $-6.44^{* * *}$ \\
\hline$\square \mathrm{kq}$ & 0.070 & $3.93^{* * *}$ \\
\hline$\square \mathrm{qt}$ & 0.061 & $5.25^{* * *}$ \\
\hline$\square$ et & 0.001 & $11.09^{* * *}$ \\
\hline$\square \mathrm{mt}$ & 0.000 & -0.01 \\
\hline$\square \mathrm{lt}$ & 0.001 & 1.38 \\
\hline$\square \mathrm{kt}$ & -0.002 & $-1.76^{*}$ \\
\hline$\square \mathrm{tt}$ & -0.004 & $-4.34^{* * *}$ \\
\hline Adjusted $\mathrm{R}^{2}$ & 0.999 & \\
\hline
\end{tabular}

Note: *** significant at the 0.01 level; ** significant at the 0.05 level; and * significant at the 0.10 level. 
Table 2: Econometric Results: Substitution Elasticities, Scale Economies and Technical Change

\begin{tabular}{|c|c|c|c|c|c|c|c|c|}
\hline \multirow{2}{*}{$\begin{array}{c}\text { SIC } 2297 \\
\text { Year }\end{array}$} & \multicolumn{6}{|c|}{ Substitution Elasticities } & \multirow{2}{*}{$\begin{array}{c}\text { Scale } \\
\text { Economies }\end{array}$} & \multirow{2}{*}{$\begin{array}{c}\begin{array}{c}\text { Technical } \\
\text { Change }\end{array} \\
\text { TC }\end{array}$} \\
\hline & $\sigma \varepsilon \mu$ & $\sigma \varepsilon l$ & $\sigma \varepsilon \kappa$ & $\sigma \mu l$ & $\sigma \mu \kappa$ & $\sigma l \kappa$ & & \\
\hline 1958 & 0.093 & -0.122 & 0.686 & 0.603 & 1.244 & 0.689 & 1.121 & 0.012 \\
\hline 1959 & 0.089 & -0.227 & 0.711 & 0.567 & 1.224 & 0.689 & 1.231 & 0.018 \\
\hline 1960 & 0.091 & -0.273 & 0.686 & 0.576 & 1.230 & 0.668 & 1.341 & 0.025 \\
\hline 1961 & 0.098 & -0.273 & 0.691 & 0.572 & 1.228 & 0.668 & 1.371 & 0.027 \\
\hline 1962 & -0.026 & -0.446 & 0.683 & 0.552 & 1.216 & 0.687 & 1.392 & 0.028 \\
\hline 1963 & -0.031 & -0.528 & 0.676 & 0.543 & 1.213 & 0.675 & 1.236 & 0.019 \\
\hline 1964 & 0.074 & -0.458 & 0.666 & 0.557 & 1.223 & 0.638 & 1.287 & 0.022 \\
\hline 1965 & 0.002 & -0.432 & 0.641 & 0.581 & 1.231 & 0.658 & 1.202 & 0.017 \\
\hline 1966 & -0.025 & -0.481 & 0.513 & 0.627 & 1.270 & 0.598 & 1.131 & 0.013 \\
\hline 1967 & 0.016 & -0.518 & 0.620 & 0.577 & 1.233 & 0.631 & 1.143 & 0.015 \\
\hline 1968 & -0.169 & -0.552 & 0.667 & 0.550 & 1.213 & 0.709 & 1.097 & 0.012 \\
\hline 1969 & -0.227 & -0.760 & 0.596 & 0.565 & 1.219 & 0.676 & 0.999 & 0.007 \\
\hline 1970 & -0.148 & -0.821 & 0.616 & 0.542 & 1.212 & 0.653 & 1.030 & 0.009 \\
\hline 1971 & -0.266 & -1.240 & 0.445 & 0.571 & 1.234 & 0.574 & 0.869 & 0.000 \\
\hline 1972 & -0.241 & -0.837 & 0.635 & 0.530 & 1.205 & 0.687 & 0.805 & -0.004 \\
\hline 1973 & -0.107 & -0.630 & 0.668 & 0.535 & 1.208 & 0.684 & 0.969 & 0.006 \\
\hline 1974 & 0.150 & -0.507 & 0.737 & 0.482 & 1.198 & 0.638 & 0.982 & 0.007 \\
\hline 1975 & 0.198 & -0.398 & 0.715 & 0.523 & 1.214 & 0.616 & 0.953 & 0.006 \\
\hline 1976 & 0.157 & -0.506 & 0.763 & 0.450 & 1.190 & 0.650 & 0.886 & 0.001 \\
\hline 1977 & 0.279 & -0.411 & 0.779 & 0.441 & 1.193 & 0.612 & 0.721 & -0.009 \\
\hline 1978 & 0.231 & -0.494 & 0.787 & 0.411 & 1.185 & 0.631 & 0.509 & -0.021 \\
\hline 1979 & 0.256 & -0.556 & 0.786 & 0.394 & 1.183 & 0.606 & 0.552 & -0.018 \\
\hline 1980 & 0.316 & -0.433 & 0.804 & 0.388 & 1.184 & 0.604 & 0.569 & -0.017 \\
\hline 1981 & 0.376 & -0.364 & 0.825 & 0.359 & 1.181 & 0.592 & 0.592 & -0.015 \\
\hline 1982 & 0.458 & -0.116 & 0.827 & 0.425 & 1.197 & 0.584 & 0.761 & -0.005 \\
\hline 1983 & 0.468 & -0.030 & 0.849 & 0.406 & 1.191 & 0.619 & 0.791 & -0.003 \\
\hline 1984 & 0.425 & -0.097 & 0.841 & 0.407 & 1.189 & 0.628 & 0.804 & -0.002 \\
\hline 1985 & 0.411 & -0.062 & 0.838 & 0.428 & 1.193 & 0.643 & 0.903 & 0.005 \\
\hline 1986 & 0.385 & -0.015 & 0.839 & 0.443 & 1.194 & 0.670 & 0.946 & 0.007 \\
\hline 1987 & 0.489 & 0.077 & 0.851 & 0.440 & 1.199 & 0.630 & 0.726 & -0.005 \\
\hline 1988 & 0.458 & -0.080 & 0.858 & 0.365 & 1.184 & 0.622 & 0.608 & -0.012 \\
\hline 1989 & 0.471 & -0.102 & 0.850 & 0.375 & 1.187 & 0.600 & 0.646 & -0.009 \\
\hline 1990 & 0.423 & -0.188 & 0.851 & 0.348 & 1.180 & 0.618 & 0.724 & -0.005 \\
\hline 1991 & 0.439 & -0.133 & 0.851 & 0.366 & 1.183 & 0.619 & 0.847 & 0.003 \\
\hline 1992 & 0.480 & 0.032 & 0.840 & 0.448 & 1.201 & 0.615 & 0.890 & 0.005 \\
\hline 1993 & 0.483 & 0.024 & 0.855 & 0.410 & 1.193 & 0.626 & 0.897 & 0.006 \\
\hline 1994 & 0.489 & 0.105 & 0.865 & 0.415 & 1.194 & 0.651 & 0.827 & 0.002 \\
\hline 1995 & 0.485 & -0.066 & 0.830 & 0.431 & 1.200 & 0.574 & 0.820 & 0.002 \\
\hline 1996 & 0.432 & -0.068 & 0.854 & 0.383 & 1.185 & 0.641 & 0.937 & 0.009 \\
\hline Means & 0.205 & -0.333 & 0.746 & 0.477 & 1.205 & 0.638 & 0.926 & 0.004 \\
\hline
\end{tabular}


NOTES 